\title{
PAISAJES CURATIVOS DOMINICANOS COMO EXPRESIÓN DE LA MEMORIA CULTURAL: UNA REFLEXIÓN SOBRE SUS RIZOMAS
}

\author{
Healing Dominican landscapes as an expression of cultural \\ memory: a reflection on their rhizomes
}

\section{Jana Pesoutova}

Doctora en Arqueología. Universidad de Leiden, Holanda. Correo-e: janapesoutova@hotmail.com

Recibido: 13/10/2019 • Aprobado: 6/11/2019

Cómo citar: Pesoutova, J. (2019). Paisajes curativos dominicanos como expresión de la memoria cultural: una reflexión sobre sus rizomas. Ciencia y Sociedad, 44(4), 51-68. https://doi.org/10.22206/cys.2019.v44i4.pp51-68

\begin{abstract}
Resumen
Este artículo expone algunas de las principales ideas recogidas a través del estudio de las prácticas actuales de sanación en Cuba y República Dominicana y sus antecedentes históricos. ${ }^{1}$ El estudio sitúa la importancia de la continuidad de prácticas curativas dentro del rico simbolismo del paisaje y explora el concepto de memoria cultural por su potencial para complementar y vincular los datos sobre las historias medicinales, las profundas transformaciones demográficas y los paisajes curativos después la conquista europea. El análisis se desarrolla, esencialmente, a través de datos obtenidos por trabajos de campo etnográficos llevados a cabo en regiones de ambas islas, complementados por información recopiladas de fuentes históricas.

\footnotetext{
${ }^{1}$ Este artículo se basa en la ponencia presentada en el evento organizado por el proyecto NEXUS 1492 conjuntamente con el Centro Cultural Eduardo León Jimenes el INTEC y otras instituciones dominicanas. Tuvo lugar el 4 de mayo 2019 y su objetivo principal fue exponer algunos de los principales resultados del proyecto NEXUS 1492, además de realizar la apertura de la exposición Lazos Caribeños. La ponencia también resume algunos de los argumentos expuestos más ampliamente en la disertación doctoral de la autora Indigenous Ancestors and Healing Landscapes que puede ser consultada online en: https://openaccess.leidenuniv.nl/handle/1887/68891
}

\begin{abstract}
This articles summarizes some of the insights gathered through the study on current healing practices in Cuba and Dominican Republic and their historical background. ${ }^{2}$ The study situates the continuous importance of the healing practices within the rich landscape symbolism. The concept of the cultural memory is explored for its potential of complementing data about medicinal histories and profound demographic and landscapes transformation which shaped the healing landscapes after the European conquest. The analysis is developed essentially through data obtained from ethnographic fieldwork carried out in regions of both islands combined with information retrieved from historical sources. In this article his approach

\footnotetext{
2 This article is based on the presentation given at the event organized by the NEXUS 1492 project with the Eduardo León Jimenes Cultural Center, INTEC and other Dominican institutions. It took place on May 4, 2019 and its main objective was to expose some of the main results of the NEXUS 1492 project, in addition to opening the Lazos Caribeños exhibition. The paper also summarizes some of the most widely presented arguments in the doctoral dissertation of the author Indigenous Ancestors and Healing Landscapes that can be consulted online at: https://openaccess.leidenuniv.nl/handle/1887/68891
} 
En este artículo su enfoque resalta las problemáticas cerca los estudios de las herencias cultuales indígenas en el contexto de prácticas curativas y aborda en general cómo la gente se relaciona con los ancestros indígenas hoy en República Dominicana.

Palabras clave: paisajes curativos; memoria cultural; culturas medicinales; herencia cultural; ancestros indígenas.

\section{Introducción}

Dentro del proyecto Nexus 1492, la investigación que aquí se presenta fue el núcleo de la disertación doctoral titulada Indigenous Ancestors and Healing Landscapes, la cual se enfocó en los paisajes curativos como una expresión de la memoria cultural. Al combinar los datos del trabajo de campo etnográfico y el análisis histórico crítico, este estudio abordó las prácticas curativas actuales y su historia en relación con los procesos de transformación generados por la invasión y colonización europea en los espacios caribeños que hoy constituyen la República Dominicana y Cuba.

La aplicación del concepto de memoria cultural en el estudio del contexto dominicano se fundamenta en la necesidad de reconocer y percibir la trayectoria de creencias populares y prácticas curativas contemporáneas en su relación con el patrimonio indígena. Ideas que contradicen las narrativas predominantes y ampliamente aceptadas en la historia nacional de República Dominicana, en la cual se postula la total desaparición de los indígenas debido a la conquista y colonización europea. En este contexto, el concepto de "memoria cultural" contribuye a comprender cómo las personas se relacionan con el pasado a través de las prácticas de sanación, y cómo estas prácticas son a su vez continuidades y/o reinterpretaciones de creencias, conocimientos y costumbres del pasado.

La memoria cultural es un concepto derivado de la teoría de Assmann (2011) sobre el papel que el highlights the issues surrounding the studies of indigenous heritage within the context of healing practices and addresses in general how people relate to indigenous ancestors today.

Keywords: Healing landscapes; cultural memory; medicinal cultures; cultural heritage; indigenous ancestors.

pasado tiene en construir nuestro mundo, formas en cuales se presenta hoy y así los motivos que nos llevan a recordarlo. En síntesis, memoria cultural engloba memoria colectiva (80-100 ańos) pero también información de periodos anteriores a cuatro generaciones. Según Assmann, estas memorias pueden ser guardadas en símbolos, paisajes, textos, fiestas, rituales, música, y acciones artísticas, especialmente narrativas, cuyos contenidos tratan de la vida y el mundo.

En este caso, el uso del concepto no se limita a la discusión del patrimonio indígena presente en las sociedades actuales, sino se usó para entender los mecanismos de transmisión de las culturas medicinales; estos procesos, así como el conocimiento ancestral, se transmiten consciente e inconscientemente, por ejemplo, por prácticas corporales, narrativas, celebraciones patronales etc. Este término nos permitió abordar cómo la gente se relaciona con los ancestros indígenas y cómo esta memoria es moldeada por la producción de conocimiento en dominios públicos e informales. Así se pudieron describir y entender mejor las prácticas curativas ejecutadas en sitios como el ingenio azucarero Sepi Sepi (Cepi Cepi) o lugares ancestrales como cueva de Maná, donde los ancestros son consultados y conmemorados a través de las fiestas religiosas.

El concepto de paisajes de sanación o paisajes curativos contribuyó a resumir o reunir todos los agentes que promueven la sanación física, mental y espiritual de individuos y comunidades. Esta definición nos permitió explorar las cualidades biomédicas 
de las plantas, así como las percepciones ecológicas y medicinales culturalmente codificadas, que a menudo se traducen en interacción con los seres divinos y ancestrales que residen o se manifiestan en lugares, en la vegetación u otros aspectos naturales. El concepto de paisaje curativo se basa en trabajos de Russo (2008) y su concepto healing landscape y Gesler (1993) y su concepto therapeutic landscape e integra los conocimientos de estudios botánicos (Acevedo-Rodríguez \& Strong, 2012; Brendbekken, 1998; Roig \& Mesa, 1974; Portorreal, 2011; Germosén y Robineau, 2005; Ososki , 2004; QuirosMoran, 2009), antropológicos (Cabrera 1993; Bolívar Aróstegui, González Díaz \& Río Bolívar del, 1998) con teorías del paisaje (Sauer, 1925; Ingold, 2002; Bender, 2002; Bollig \& Bubenzer, 2009; Hermans, Koles \& Renes, 2013) y datos obtenidos por medio de observación participativa y entrevistas durante trabajos de campo sobre prácticas curativas actuales. En combinación, estos conceptos sirvieron para abrir la discusión sobre cómo el bienestar colectivo y la sanación pueden comprenderse a través de estudios de memoria cultural inclusiva que aborden periodos de historias traumáticas o contestadas.

Esta investigación comenzó con un análisis de la historia colonial de los pueblos indígenas y su papel en las historias medicinales de la región, consistente en una lectura detallada, contextualización histórica y análisis textual de los principales documentos primarios y secundarios. El principal corpus de conocimientos se originó a través del trabajo etnográfico de campo, las interacciones con expertos locales e informantes claves. El conjunto de datos fue recopilado durante la participación en diferentes rituales, conversaciones informales y entrevistas semiestructuradas con preguntas abiertas en diferentes entornos. Las entrevistas fueron grabadas, y se mantuvo un registro con resúmenes diarios y documentación fotográfica.

La selección de los lugares fue coherente con los objetivos del proyecto Nexus 1492 con respecto a las transformaciones de las culturas indígenas generadas por la colonización europea. Por lo tanto, se prestó mayor atención a los lugares donde había indicios arqueológicos o históricos de contacto cultural entre diferentes grupos.

Después de abordar brevemente algunos puntos de las historias demográficas y medicinales de la República Dominicana, procederé a analizar cómo los miembros de las comunidades relacionan charcos y cuevas con el pasado indígena.

\section{Los indígenas en las páginas blancas de la historia medicinal}

El impacto del colonialismo europeo sobre la salud humana en el llamado Nuevo Mundo, incluye desde la propagación de enfermedades hasta el intercambio de conocimientos médicos, pasando por cambios demográficos; elementos que han dado forma a las tradiciones curativas contemporáneas de las regiones estudiadas. A pesar del continuo e importante papel de las prácticas curativas tradicionales para las sociedades actuales, estas están insuficientemente estudiadas y su formación histórica sigue siendo bastante enigmática.

La primera parte del estudio se centró en las transformaciones demográficas coloniales, incluyendo los cambios culturales y religiosos y su papel en las historias medicinales de la región. Impulsado por el objetivo principal de investigación del proyecto Nexus 1492, este estudio destacó la historia colonial de los pueblos indígenas en ambas islas después del período de encomiendas, considerando su relación con los espacios donde se llevó a cabo el trabajo de campo.

La revisión general de las historias demográficas y medicinales de La Española y Cuba sugiere que la hipótesis del etnógrafo Fernando Ortiz (1995) sobre el fracaso de la transculturación indígena necesita ser revisada. En primer lugar, algunos registros guardan referencias sobre la presencia y la integración social de los descendientes de indígenas 
en varios asentamientos urbanos y rurales de ambas islas durante el período colonial (para la Española: Echagoian, 1565; Alcocer, 1650; Exquemelin, (1678 [1971]); Moreau de Saint-Mery, 1796; Rodríguez Demorizi, 1945; Gil-Bermejo García, 1983; Blanco Díaz, 2009; Mira Caballos, 1997; Rodríguez Morel, 2011, y 2015; Anderson-Cordova, 1999 y 2017; Yaremko, 2016). De hecho, los descendientes de indígenas tuvieron una oportunidad de contribuir genética y culturalmente a la fundación de diferentes asentamientos cubanos y dominicanos.

Después del desmantelamiento de la encomienda, los indígenas se asentaron en las regiones del cabo de San Nicolás, el cabo de Tiburón, la provincia de Ciguayos y Samaná (Blanco, Díaz 2009; Mira Caballos, 1997). En la segunda mitad del siglo XVI, los indígenas residían en Boyá, La Mona, Sabana, Santo Domingo, La Yaguana, Yaquimo y en asentamientos cercanos a La Vega, Buenaventura y Santa Cruz de Acayagua (Blanco Díaz, 2009; Rodríguez Morel, 2011 y 2015; Echagoian, 1565). Las fuentes del siglo XVII mencionan brevemente a los descendientes de indígenas en Azua, Boyá, Cibao, Yaguana, Tortuga y a orillas del río Yguamo (Gil-Bermejo García, 1983; Rodríguez Demorizi, 1945 y 1957; Rodríguez Morel, 2015). A finales del siglo XVIII, los habitantes de Bánica y Boyá son reconocidos como descendientes de indígenas (Moreau de Saint-Méry, 1796; Rodríguez Demorizi, 1957). A pesar de que en este período muchas personas se identificaron como tales, su identidad fue puesta en duda porque, según Moreau de Saint-Méry (1796), esta no pudo ser probada históricamente. Algunas personas de ascendencia mixta (indígenas, africanas y europeas) fueron registradas por otras fuentes en Santiago. A finales del siglo xIx los habitantes de Boyá aparecen descritos como un pueblo de composición racial mixta que incluye rasgos fenotípicos que se consideran típicos de los pueblos indígenas de las Américas (Monte y Tejada, 1890). Como ilustran las historias de Boyá, Jiguaní, Caney o Guanabacoa (Badura, 2013; Portuondo Zúñiga, 2012; Valcárcel
Rojas, 2012; Valcárcel Rojas \& Pérez Concepción, 2014; Ulloa Hung \& Valcárcel Rojas, 2016; Vega Suñol, 2014; Pesoutova, 2019), los indígenas vivían en asentamientos que no estaban aislados, sino cerca de importantes centros económicos.

Algunas referencias históricas a los pueblos indígenas de La Española y Cuba sugieren revisar la hipótesis de la transculturación indígena fracasada. En estas, la población indígena parece constituir la base de la primera sociedad colonial criolla. También, es necesario destacar que la población indígena estaba compuesta por personas de origen local y no local, y que las etiquetas que definieron sus identidades fueron impuestas por los regímenes coloniales, por lo que probablemente ignoraban la auto-identificación con sus propios antepasados y su patrimonio. El énfasis colonial en la raza no debe hacernos perder de vista las múltiples formas en que los descendientes de los indígenas fueron capaces de mantener las distintas identidades étnicas, las culturas medicinales e intercambiar con otros ancestros.

A pesar de esto, la demografía se vio profundamente influenciada por el declive de los pueblos indígenas, y otros aspectos como la trata transatlántica de esclavos, una serie de olas de inmigración (incluyendo Canarias y el Caribe) además de otros acontecimientos históricos locales como las devastaciones del Norte, epidemias, movimientos de población después de la Paz lograda con el "Tratado de Basilea" en 1795, ocupaciones extranjeras, profundos cambios económicos, industrialización, reformas agrarias y cambios tecnológicos, etc.

La transferencia de conocimientos botánicos y medicinales refleja la complejidad de las historias demográficas y sus particularidades locales, incluyendo las diferencias de poder y las variadas maneras de resistencia a este. Autores como Pané (1498 [2011]), Fernández de Oviedo (1535 [2002]), Monardes (1580), Méndez Nieto (1989), Breton (1665[2015]), Sloane (1707) refieren la contribución indígena a la biografía de 
los paisajes curativos. En la década de 1550, cuando ya se consideraban extintos los indígenas, una vecina de Puerto Plata se quejaba de que todas las cacicas o mujeres indígenas de La Española conocían las "hierbas para hacer bien y mal" (Deive, 2002).

Otra fuente indica que algunos conocimientos medicinales indígenas se preservaron hasta finales del siglo Xvi. Se refiere al Lic. Juan Mendéz Nieto, quien trabajó como cirujano en Santo Domingo y comentó sobre las prácticas indígenas relacionadas con la maternidad y el parto, las cuales consideró más adecuadas que las prácticas españolas de la época (1611). De manera similar, el doctor Sloane, en Jamaica (1707), menciona varias prácticas medicinales (entre ellas el uso de sangría, purga, ventosas, y escarificación) de los pueblos indígenas, algunos de ellos con orígenes en la Florida, Misquitos u otras regiones, que fueron esclavizados por los españoles. Sloane describe también métodos comunes entre ancestros de orígenes africanos, los que según su reporte solían hacer las ventosas con higüeros, y el vendaje con una mezcla de arcilla.

Según estos reportes está claro que la presencia europea y africana también impactó profundamente el universo curativo caribeńo. Influencias que los curanderos del otro lado del Océano Atlántico han moldeado profundamente a través de ricas prácticas medicinales actuales.

A pesar de los prejuicios, algunas fuentes proporcionan extraordinarios relatos de prácticas de curación originarias del África Occidental y de cómo ancestros africanos y europeos debieron construir sus conocimientos medicinales en entornos desconocidos por ellos. En general, las fuentes históricas y etnográficas coloniales indican que las actuales prácticas de curación están formadas por conocimientos medicinales creados a partir de la alta movilidad intra e interregional de sus portadores, y debido a encuentros interculturales que dieron lugar a visiones del mundo diversas, las que necesariamente impactaron e impactan dichas prácticas
(Pesoutova, 2019). Los conocimientos botánicos constituyen uno de los índices que revelan más abiertamente estos cambios y movilidades demográficas. Por otro lado, el significado múltiple otorgado a algunos lugares y el uso general del paisaje por los dominicanos reflejan cómo estos se vinculan consciente o inconscientemente con sus antepasados indígenas.

\section{Charcos como fuentes de memorias}

Los paisajes dominicanos tienen una gran importancia para la salud y el bienestar individual, así como para la calidad de vida comunitaria. Los paisajes curativos actuales incorporan un rico simbolismo que codifica el significado de los recursos naturales en la vida cotidiana, la agricultura, el uso ritual y en periodo de enfermedades. Estas diversas formas de usos del paisaje (Dwelling en Ingold, 2002) también muestran cómo los habitantes actuales se relacionan con el pasado de manera más o menos consciente. Aunque es importante resaltar, que las varias maneras de inhabitar el paisaje también incluyen continuidades de conocimientos pasados de forma inconsciente relacionadas con los indígenas. Estas, pueden estar presentes a través del "habitus", las prácticas culturales o el simbolismo de los paisajes circundantes.

El ámbito del conocimiento ecológico, la alimentación, la artesanía y la agricultura también reflejan las continuidades culturales y lingüísticas y los cambios en el uso de la flora desde la época precolonial y colonial temprana. Varios elementos de las prácticas curativas caribeñas actuales y del conocimiento ecológico guardan similitud con los relatos históricos y etnográficos del Caribe y Sudamérica continental, pero también de África y Europa. Estas similitudes básicamente se observan sobre las ideas asociadas a las causas de enfermedades; la referencia a paisajes animados, y "bańos" en lugares sagrados. De igual manera, los múltiples significados de ciertas plantas como la ceiba, el tabaco, la calabaza 
o lugares como las pozas de agua, y cavernas, indican claramente un proceso de transculturación en el que la creatividad y las creencias de las sociedades criollas aportaron los significados actuales (figuras 1-4).
Algunos de ellos fueron moldeados en conjunción con la memoria de los antepasados indígenas y un amplio conjunto de conocimientos derivados de su herencia cultural.

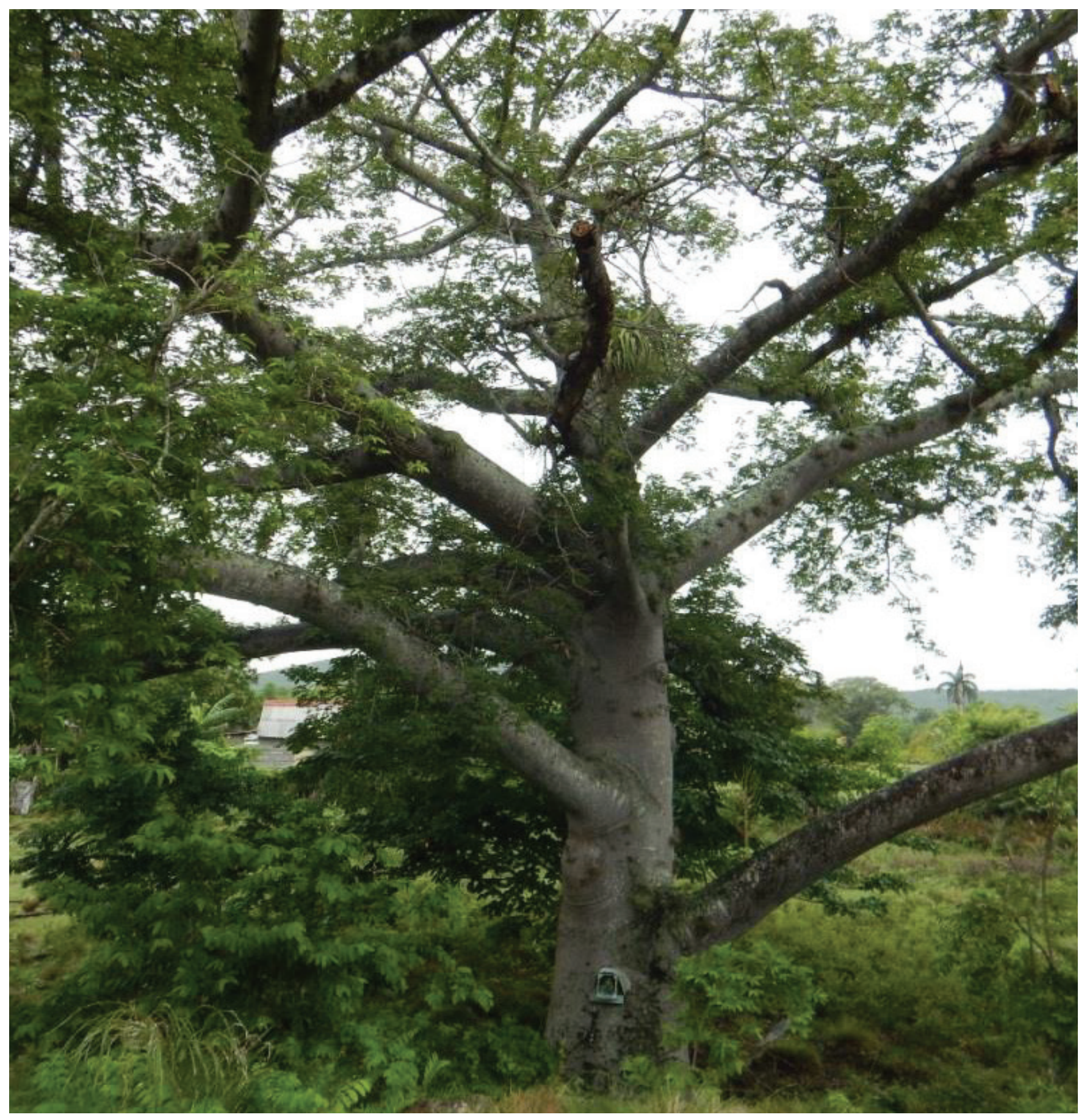

Figura 1. Árbol de ceiba con imagen de Virgen de La Caridad colgada en el tronco. Managuaco, Cuba. Fuente: foto de Jana Pesoutova, 2014. 


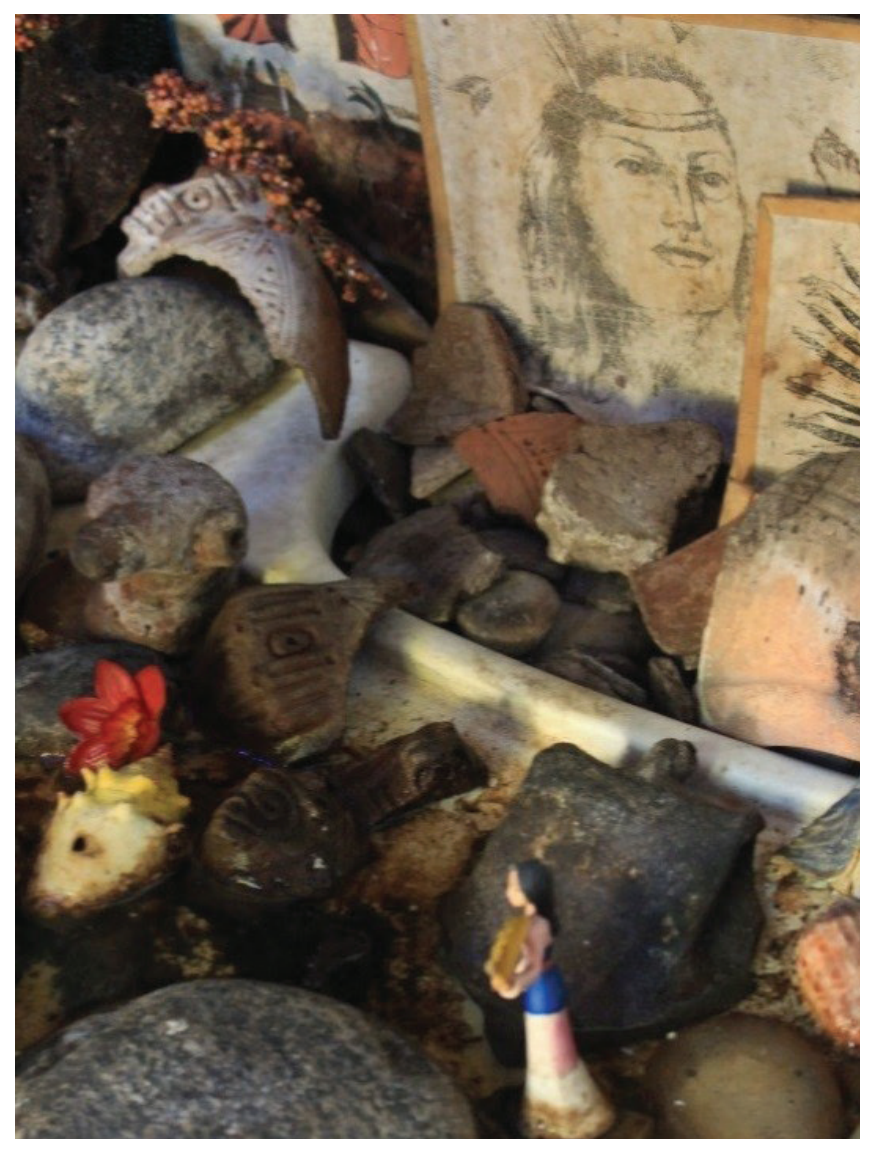

Figura 2. Detalle del parte de un altar dedicado a antepasados indígenas. Imbert, provincia Puerto Plata. República Dominicana.

Fuente: foto de Jana Pesoutova, 2014.

Una forma de ilustrar los procesos de construcción de la memoria cultural sobre los pueblos indígenas lo constituyen los charcos y las cuevas. Charcos, cascadas y ríos son importantes lugares de memoria de los ancestros indígenas en todas las regiones de República Dominicana. Los cuerpos de agua tienen múltiples significados, son lugares donde se pueden percibir tanto a los antepasados potencialmente peligrosos como a los fallecidos, pero también pueden servir para desarrollar la virtud de sanar.

Las narraciones sobre charcos profundos suponen advertencias y llamados a la cautela, ya que estos lugares pueden ser peligrosos para los humanos: su alma puede ser arrebatada y llevada al dominio subacuático de los espíritus. Los relatos sobre niños, o personas que son llevados por estas fuerzas se asemejan, en cierto grado, a los de las comunidades indígenas del continente. Los Ashaninka y Araweté, por ejemplo, también hablan de seres invisibles que habitan las fuentes de agua y que han estado engañando, seduciendo y secuestrando a niños, mujeres y viajeros (sus almas) que llevan hasta sus casas subacuáticas (Santos-Granero, 1998; Viveiros Castro, 1998).

Estos cuerpos de aguas también se usan para baños, iniciaciones y fiestas patronales donde los antepasados indígenas están presentes y reciben ofrendas. Uno de estos lugares de conmemoración de los antepasados indígenas era El charco de Tamares, situado en el poblado de La Jaiba, cerca de Estero Hondo en la provincia de Puerto Plata. La tradición oral local lo identifica como la morada de ancestros indígenas (sus espíritus). Durante varias generaciones este pequeño charco fue un lugar de celebración de la Fiesta de San Miguel, durante la cual también se recordaban los ancestros indígenas a través de ofrendas de comida que dos hermanos mellizos llevaban al charco por encargo de una curandera. Rodeados de sitios arqueológicos indígenas los residentes de La Jaiba están conscientes de la presencia histórica de estos antepasados, al punto que para algunos residentes la herencia cultural material tiene un simbolismo espiritual importante. Una de las historias orales relacionadas con este lugar así lo ilustra:

Alli arriba (del charco) habia una vivienda y habia un niño que tenía como catorce años y nunca caminaba, él era haitiano y en el conuco se encontró una Virgen de los Indios y, oye esto, el chico se paró caminando ven mamá, ve mamá y empieza a caminar. $Y$ entonces esa madre se bajó de allí, su mama se mudó de alli y empezó a vela de nueve dias durante la fiesta de San Miguel y esta Virgen sudaba alli en el altar. Pero la robaron, alguien la robó (entrevista grabada 
en 04/07/2013 en Charco de Tamaré, junto con Adriano Rivera)

En otro orden, la historia del Charco de Tamaré ilustra al mismo tiempo cómo conflictos causados por la intolerancia a otras religiones pueden contribuir a que estas celebraciones sean estigmatizadas. Aspecto que también impacta sobre las vías como se trasmite el conocimiento sobre el significado del lugar.

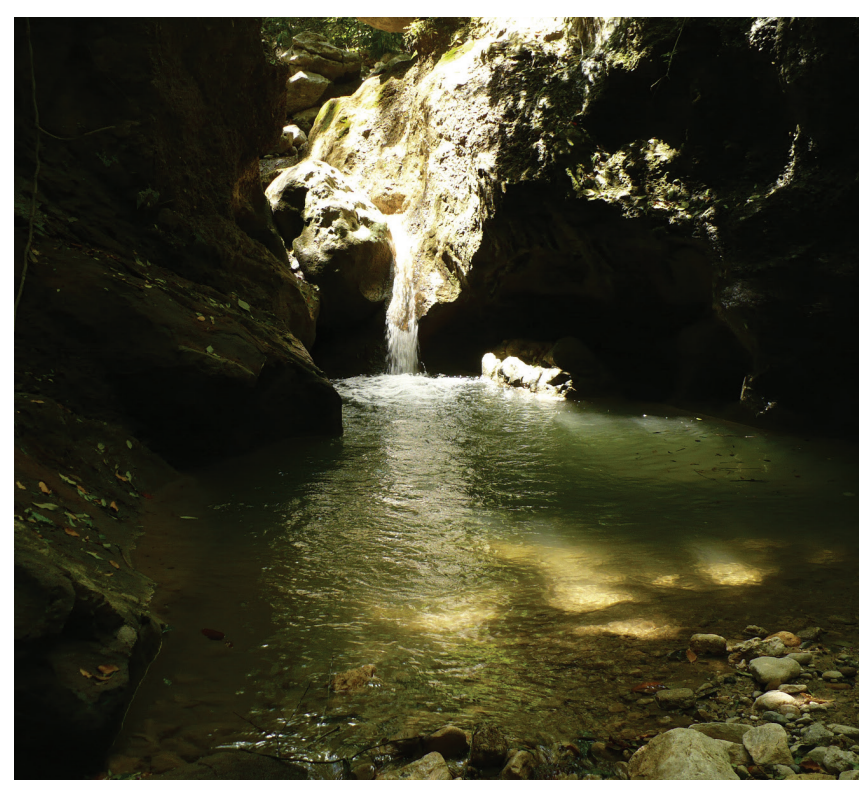

Figura 3. Charco de Tamaré cerca de La Jaiba, provincia. Puerto Plata. República Dominicana.

Fuente: foto cortesía de Jorge Ulloa Hung, 2014.

La asociación de los cuerpos de agua con los antepasados indígenas parece estar distribuida en toda la isla. Los múltiples significados atribuidos a los cuerpos de agua en Bánica son ilustrativos de las transformaciones culturales desencadenadas por el colonialismo. Algunos Baniqueros y peregrinos perciben la agencia de los ancestros en ciertas partes del río Aitibonito y algunos manantiales circundantes. Varias partes del río Aitibonito, así como los manantiales, están asociados con poderes indígenas y divinos. Por esta razón los invocan durante celebraciones patronales y rituales de sanación individuales. Uno de los rituales de curación al que logramos asistir fue al del Sr. Mero de los Santos y su esposa Rosa, residentes de Pedro Santana. Como complemento al tratamiento con hierbas, la pareja de los Santos fue a un manantial en La Descubierta (Pedro Santana) donde restablecieron relaciones positivas con misterios que viven en este manantial cercano de su antigua casa. Al ofrecer café y un higüero con maní y maíz, el señor de los Santos invocó a Dorsu, Mellizos, y — su esposa añadióel Rey del Agua.

En conversaciones anteriores y posteriores a este ritual, el señor de los Santos asoció estos seres con ancestros indígenas. Aunque no proporcionó más detalles sobre estas entidades espirituales, los mellizos $y$ Dorsu fueron invocados por sus hermanos gemelos fallecidos. Esto debe entenderse dentro de la creencia dominicana de que los gemelos nacen con el don de curar, y que si estos se desarrollan adecuadamente tales personas pueden curar a otros. Al mismo tiempo, según los devotos de la 21 División del vudú, el río Aitibonito es un dominio de Simbi Nan Dlo.

Los misterios a los que se refirió el señor de los Santos parecen tener una conexión con las creencias del Congo y Dahomey. En las creencias Congo, los niños con una distinción especial, como los gemelos (marassá), nacen en el dominio o bajo la agencia de simbi, un espíritu de localidades con rocas, barrancos, arroyos y charcos. Estos espíritus son capaces de influir en la fertilidad y el bienestar de aquellos que viven o pasan cerca, y pueden tener un impacto negativo si no son tratados con respeto (Macgaffey, 2001).

A lo largo de África Centro-Occidental tales espíritus existen bajo diferentes nombres en la creencia congo conocida como Nkisi Ntinu a Maza y en Dahomey conocida como toxosu, ambas traducidas literalmente como "El Rey del Agua” (Macgaffey, 2001; Herskovits \& Herskovits, 1933, p. 30). Toxosu, los que nacen con una distinción especial, como 
los gemelos, se convierten en espíritus de los ríos y custodian la entrada al reino de la muerte. Los toxosu están bajo el dominio del grupo de Damabala o Dambada Hwedo, poderosos ancestros desconocidos (Herskovits \& Herskovits, 1933, p. 30).

Según, los ancestros africanos pudieron vincular los charcos en La Española a sus antepasados desconocidos, que en muchos casos eran los antepasados indígenas en el contexto de La Española. Esta relación se vuelve aún más probable considerando que muchos de los sitios arqueológicos están en cercanía de los ríos. Este fenómeno ofrece una posible explicación de la distribución nacional sobre las narrativas de los charcos de agua y sus vínculos con los antepasados indígenas. Las huellas materiales (la herencia cultural material) es al fin y al cabo una herramienta mnemónica muy importante en sociedades donde es conocimiento y las tradiciones se transmiten por vía oral. Mecanismos similares pudieron preservar el conocimiento y la fe en poderes ancestrales indígenas en el poblado de Bánica.

Los baniqueros pudieron encontrar las huellas de esos ancestros desconocidos materializadas en los petroglifos en la cueva San Francisco, en restos de cerámicas, y tal vez en modificaciones humanas de la flora. Aunque no conocemos a qué momento se remonta la asociación de los cuerpos de agua con los ancestros indígenas, es evidente que algunos manantiales, como La Zurza y un manantial de azufre en Bánica, eran bien conocidos y apreciados para la cura de enfermedades de la piel desde finales del siglo XviII (Moreau de Saint-Méry, 1796).

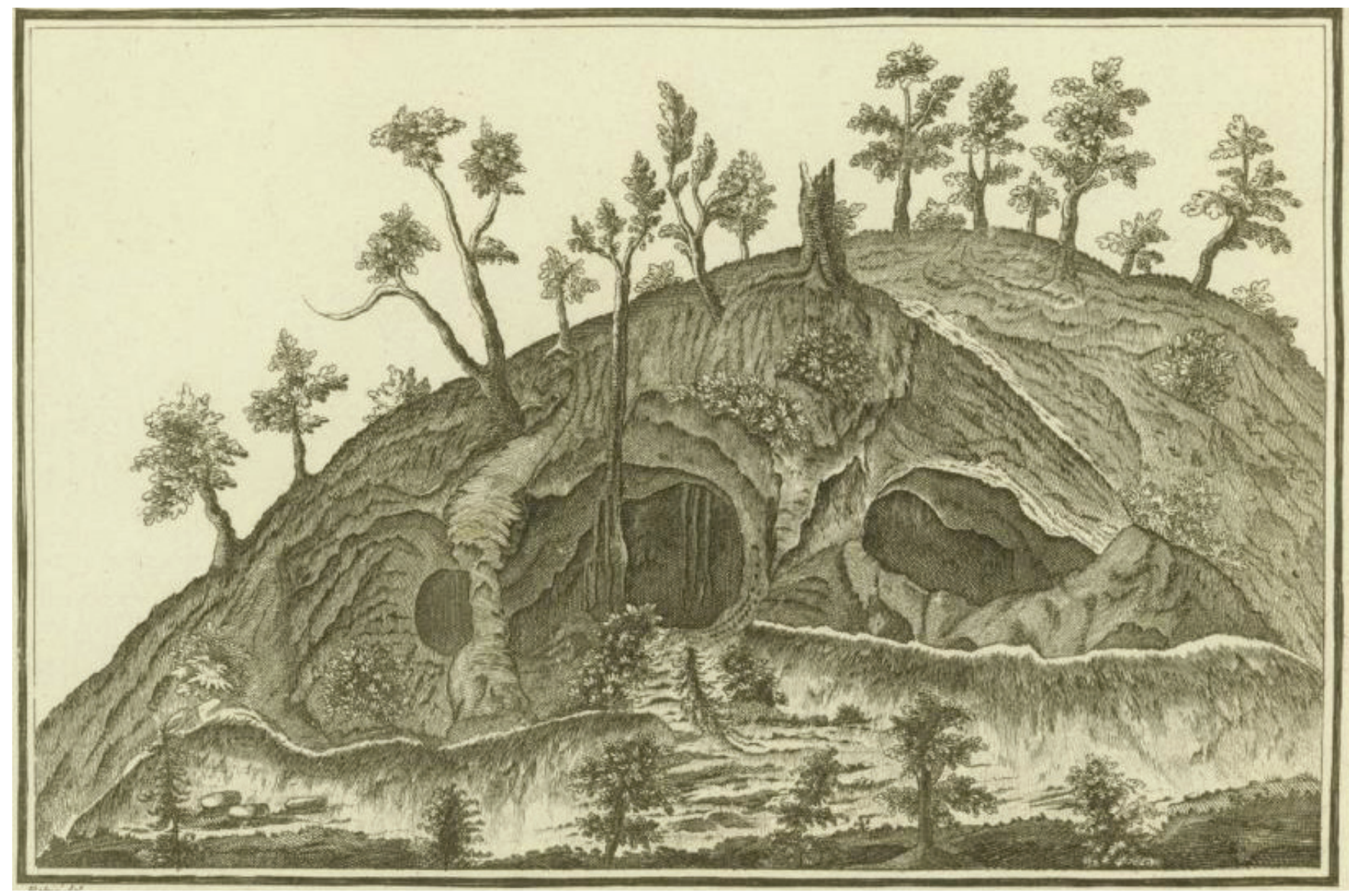

Figura 4. Cuevas de Bánica en Ponce. Grabado presente en la obra de Louis Elie Moreau de Saint-Méry (1796). 


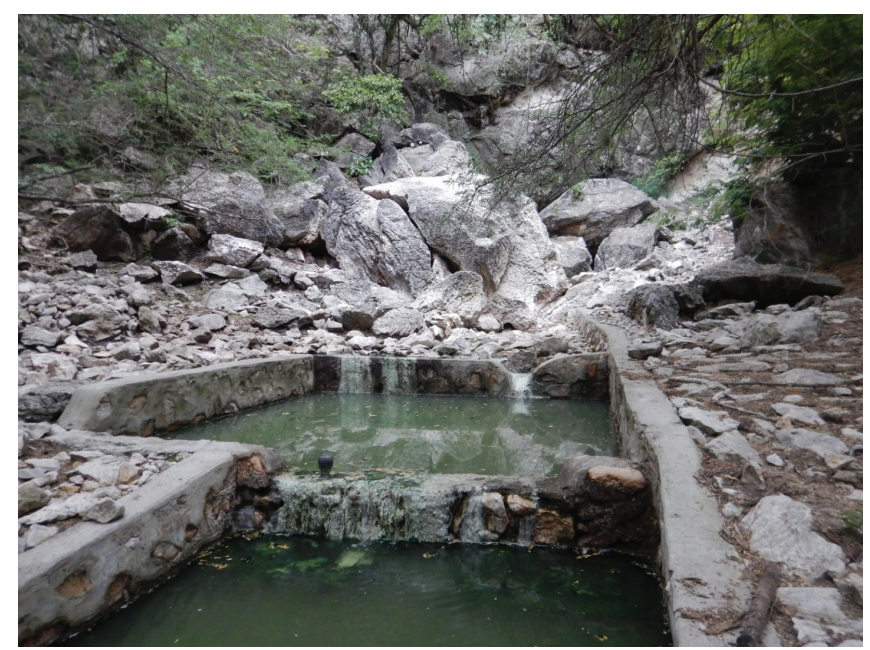

Figura 5. Manantial de La Zurza en Bánica.

Fuente: foto de Jana Pesoutova, 2014.

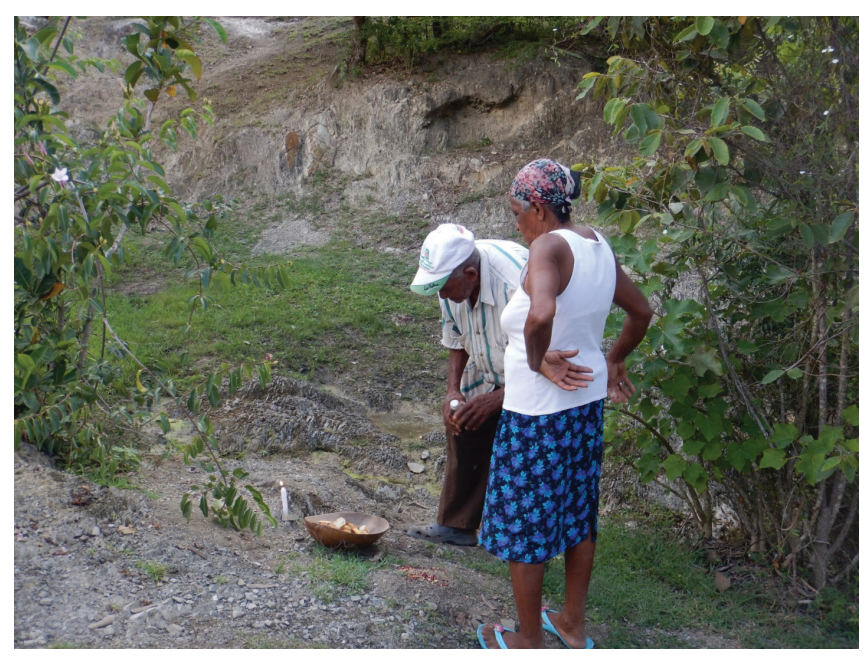

Figura 6. El señor Mero de los Santos y su esposa durante la celebración de un ritual para mejorar su salud.

Fuente: foto de Jana Pesoutova, 2014.

Al considerar que según Moreau de Saint-Méry (1796), los habitantes de Boyá y Bánica continuaron autoidentificándose con sus antepasados indígenas hasta finales del siglo Xviı, podemos valorar paralelismos entre los Gemelos Divinos mencionados por Fray Ramón Pané (1498 [2011]), de la Borde (1674 en Gullick, 1976), o por Lalung en Dominica, en la década de 1940 (Pesoutova, 2019).
Hipotéticamente, los antepasados africanos que llegaron a Bánica pudieron identificar su "Rey del Agua" africano con la Madre del Agua (que ahora se conoce en Cuba) o con una boa misteriosa que aparece en las historias dominicanas. Los datos de campo junto a datos históricos sugieren que probablemente la Madre de Agua Cubana tenga un vínculo histórico con el "Dueño del Agua", una figura común entre los hablantes arahuacos en el continente, y también es posible que esta también tenga un vínculo con la narrativa sobre una culebra conocida hasta hoy en Bánica.

Una vez más el testimonio de Mero de los Santos es ilustrativo en este caso "los viejos de antes decían que en el cerro de San Francisco vivia un culebrón grande que cantaba como un gallo. Se sabia que tenia un misterio por el canto que hacia y la gente le temía". Otro vecino de Bánica, Benjamín de Alcántara, añadió:

Estas culebras bajaban del cerro al río cuando estaba lloviendo mucho, de esta manera se formó una corriente y se decía que llevaban un diamante. Cuando se arrojaron al rio, cuando se arrojaron al mar, cuando iban alli, dijeron: malditos los que me vieron y no me mataron.

Una narración con un personaje de características similares fue descrita por primera vez en las Antillas Menores por Bouton en 1640. Tres siglos más tarde, Taylor (1941) (citado en Gullick, 1982) en su estudio etnográfico de los Kalinago en Dominica, registró una narración local sobre una serpiente gigante, llamada Bakámo $^{3}$, que puede cantar como un gallo y en cuya cabeza se coloca un diamante. Siendo uno de los principales progenitores de la humanidad, esta serpiente divina, tiene cuerpo de serpiente y cabeza de un hombre, y puede transformarse en un humano para ayudar y aconsejar a la gente. Otra versión de

3. De Goeje (1942) menciona para El Espíritu de Agua o Madre Agua también Oriyu para Arauaco hablantes, Okoyumu como otro Espíritu de Agua y Tiempo, pero también Warubuši, serpiente/ persona. 
esta narrativa menciona a dos hermanos que han recibido arrowroot (Maranta arundinacea) y el tabaco por los encantos de una serpiente que vive en una caverna (Taylor, 1952, p. 273).

En el contexto de Bánica es posible que la narración sobre la Culebra Grande (el Gran Majá en el caso cubano) podría haber servido de base para el sincretismo o más bien para una sinergia simbólica con las creencias mencionadas de África Occidental. La misma base, tal vez sirvió para el vínculo general de los charcos con los antepasados "desconocidos", los que en general también podrían fusionarse con narrativas sobre otros seres de agua como los miengus, seres africanos parecidos a sirenas de pelo largo que viven en los ríos y en el mar y que traen buena fortuna. De la misma manera la presencia de sitios arqueológicos indígenas en algunas zonas y las particularidades de sus desarrollos demográficos locales parecen reflejar un sincretismo entre los miengus, las indias que viven en los charcos, y las sirenas vinculadas a las mitologías europeas.

Desde la perspectiva anterior, el tema de las actuales narraciones sobre ancestros indígenas que habitan en fuentes de aguas podría tener múltiple orígenes: pueden constituir el eco de las ideas indígenas sobre los gemelos, la Madre de Agua o Bakámo, seres invisibles que habitan en las fuentes de agua y que han estado engańando, seduciendo y secuestrando a nińos, mujeres y viajeros que son trasladados al otro mundo como entre los Wayuú (Perrin, 1987). Historias que además pueden estar fusionadas con otros puntos de vista que se agregaron después de 1492.

Seres espirituales de origen africano como el Rey del Agua, Simbi, los miengus y las sirenas ilustran cómo las comunidades de las nuevas diáspora africanas y europeas se apropiaron de los espacios de acuerdo con su propia visión del mundo, las que también pueden haberse conectado con información fragmentada proveniente de la población de origen indígena precolonial.

\section{Cavernas como lugares ancestrales}

Otros lugares prominentes asociados con los ancestros indígenas son las cavernas. Las cavernas han sido inscritas en la biografía del paisaje caribeño como lugares de curación, de historias sagradas, así como espacios enigmáticos. En las tradiciones orales las cavernas figuran como sitios ancestrales, lugares donde vivían los pueblos indígenas, escondites de los cimarrones escapados durante el período colonial (ejemplo en la localidad de Gibara en Cuba) y como refugios durante los huracanes, por ejemplo, durante el huracán David (1979) en Boca Yuma; el huracán George (1998) en Mana; y el huracán Irma (2017) en Gibara.

Las cavernas en las islas caribeñas tienen múltiples significados. A menudo son misteriosas, temidas y por lo tanto evitadas. Por otro lado, los devotos cubanos y dominicanos consideran las cuevas como lugares de manifestación o agencia de seres divinos, santos y predecesores remotos, que pueden intervenir potencialmente en asuntos de bienestar humano. Los practicantes del espiritismo, la 21 División, la Regla de Ocha o santería y el Catolicismo Romano, buscan el contacto y la comunicación con esos seres en diversas cavernas para mejorar su salud y bienestar. En las islas, las cavernas frecuentemente también se asocian con los pueblos indígenas y su pasado.

En República Dominicana múltiples cavernas son activamente utilizadas para actividades rituales. En lugares como Bánica y La Mancha, las celebraciones en las cavernas se dedican a santos católicos, pero se espera que espíritus indígenas (lwa) se unan a la celebración y se dejan ofrendas para ellos en el suelo y en puntos específicos, cerca de petroglifos o en lugares asociados al agua. Al ser parte de una celebración patronal, estas conmemoraciones de los antepasados indígenas deben ayudar a establecer o mantener una relación positiva entre los devotos, los santos y los espíritus o lwas. La interacción con las fuerzas ancestrales en este contexto incluye 
expresiones de gratitud por la guía espiritual, advertencias y protección en tiempos de enfermedad o crisis. El carácter liminal de las cuevas como lugares que permiten el paso de un mundo a otro se presta a la veneración de los antepasados.

Cuando se trata de encontrar un posible vínculo respecto a la continuidad o la asociación actual de las cuevas con los ancestros indígenas es importante reconocer que su veneración, en términos generales, también es común en los rituales de la 21 División Dominicana, en el vudú haitiano, el candomblé brasileño y el Winti de Surinam. La veneración de los antepasados indígenas también reseña, en términos generales, la veneración de los ancestros en otros lugares de América y África Occidental (Central), así como las costumbres europeas de recordar a los parientes fallecidos en el Día de los Difuntos.

La creencia popular que los antepasados indígenas "vivían" en las cuevas también puede reflejar las ideas que sobre ellos se trasmiten a través de la enseñanza formal basadas en las primeras crónicas, donde se sugiriere que los Guanahatabeyes y Siboneyes vivían en cavernas (Las Casas, 1992). Al mismo tiempo, las primeras descripciones sobre las creencias ancestrales de las poblaciones indígenas de La Española describen las cuevas como espacios relacionados con seres ancestrales o divinos, por ejemplo, el Sol, La Luna, Boinayel, o un lugar para la invocación de la lluvia (Pané, 1498, [2011]). Al respecto, otros paralelismos pueden establecerse con las costumbres y creencias de otros grupos arahuaco-hablantes. Por ejemplo, entre los Wayuús la caverna Jorottuy Manna es el lugar de origen del Sol (Kaí), La Luna (Kashi) y la gente (Perrin, 1987). Junto con un pequeño pozo en el Cabo de la Vela, esta caverna es el paso a través del cual los muertos van al mundo del cielo.

La rica evidencia arqueológica de entierros indígenas en cuevas también sugiere una conexión con creencias sobre el más allá (La Rosa Corzo \& Robaína
Jaramillo, 1995; CITMA, 2007). Haciendo un paralelismo con el uso de cavernas entre los Kalinago, las cuales se utilizan para consultar a Bákamo, la Serpiente Divina que dio a la gente plantas para protegerla, es sugerente que las antiguas ofrendas indígenas en las cavernas de República Dominicana también pueden haber sido dirigidas a otros seres divinos, no solamente a los mencionados por Pané. Sin tampoco descartar que los antiguos rituales en estos contextos también podrían haber estado dirigidos a los antepasados.

Las celebraciones en Cueva de Mana y en la Cueva de Bánica integran los ricos simbolismos, enseñanzas y sabidurías de varios ancestros, que reinterpretaron esos espacios en los nuevos contextos culturales y ambientales. Ejemplos de esto es que la cueva de San Francisco, en Bánica, es ampliamente reconocida en la región por la manifestación o aparición de San Francisco (figuras 7 y 8), mientras la cueva de Mana es popular entre los devotos a San Juan en la misma zona (figuras 9 y 10).

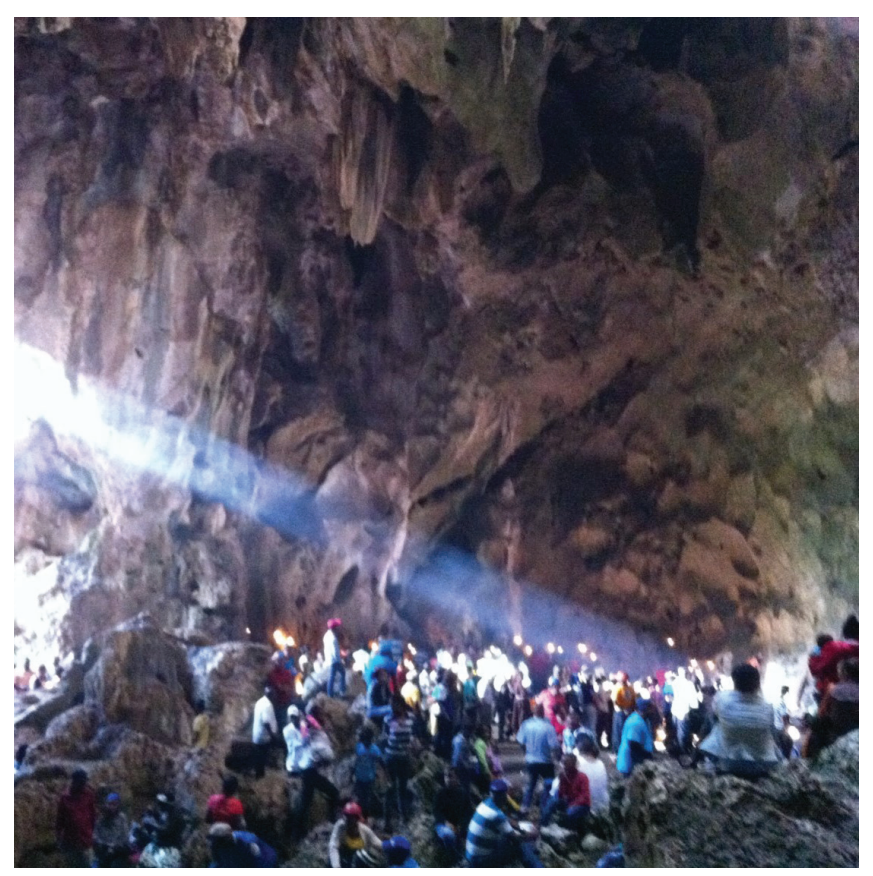

Figura 7. Cueva de San Francisco durante la celebración de este santo, Bánica. República Dominicana.

Fuente: foto de Jana Pesoutova, 2013. 

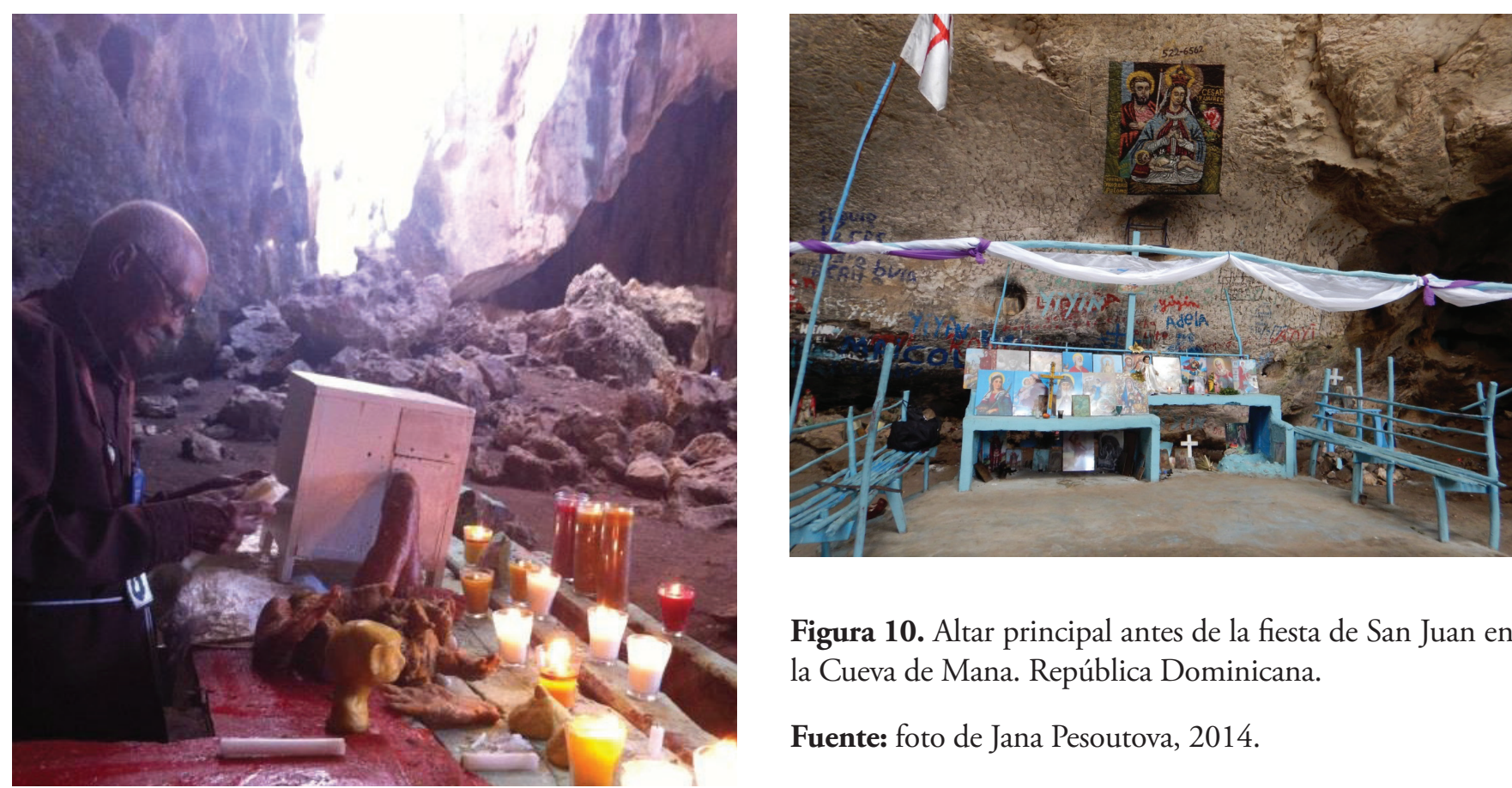

Figura 10. Altar principal antes de la fiesta de San Juan en la Cueva de Mana. República Dominicana.

Fuente: foto de Jana Pesoutova, 2014.

Figura 8. El señor León Alcántara recogiendo ofrendas durante la fiesta de San Francisco. República Dominicana.

Fuente: foto de Jana Pesoutova, 2014.

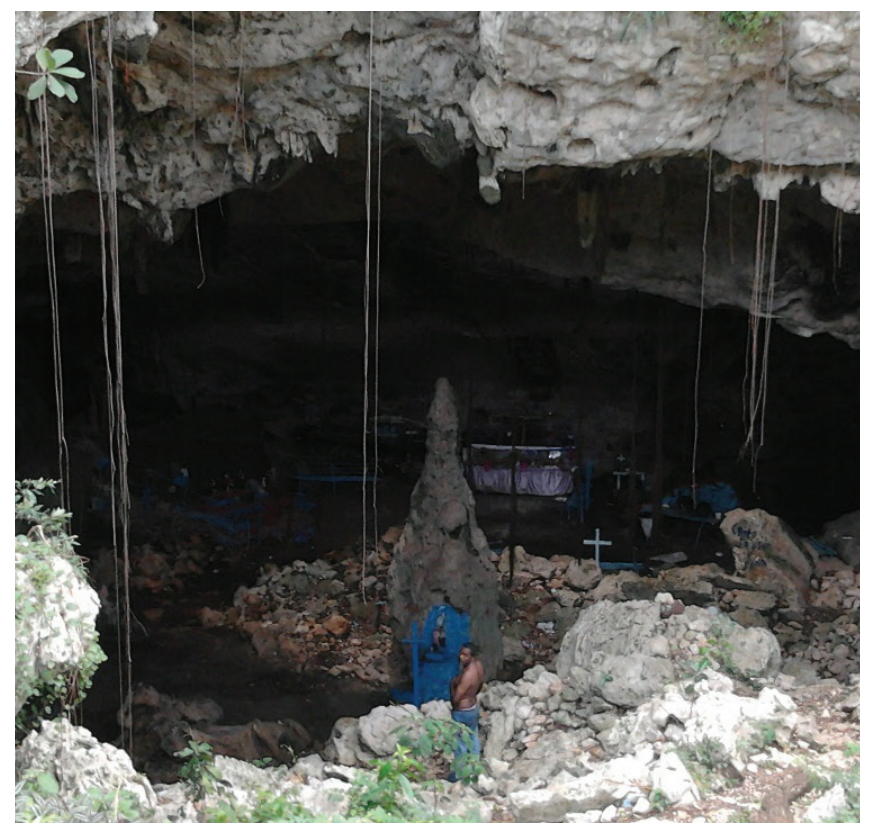

Figura 9. Cueva de Mana. El señor Jeovany Guzmán frente al altar de San Juan cerca de Yaguate.

Fuente: foto de Jana Pesoutova, 2014.

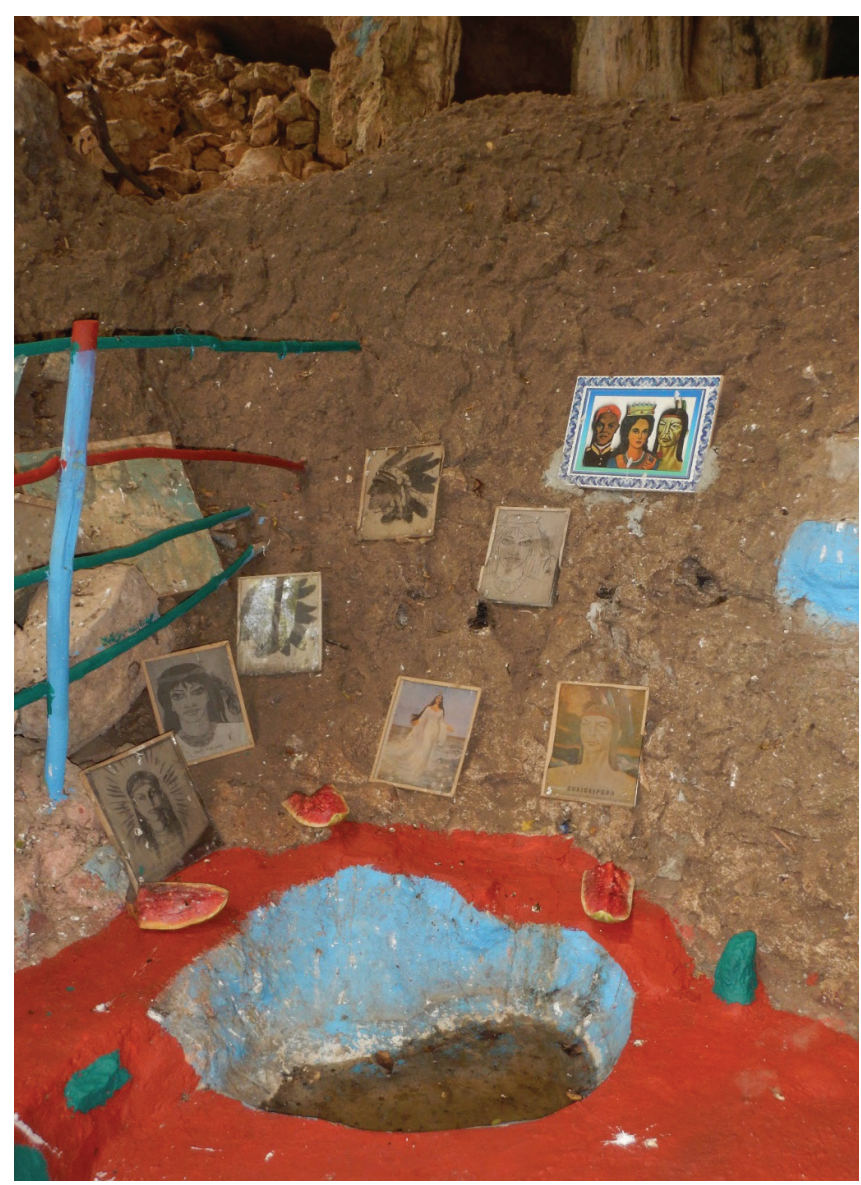

Figura 11. Detalle del Altar en Cueva de Mana.

Fuente: foto de Jana Pesoutova, 2014. 
En ambas cuevas también se llevan ofrendas y se invocan a "los indios". Las dos fiestas antes referidas ilustran cómo el significado de lugares de este tipo ha sido profundamente transformado durante los últimos quinientos años, pero a pesar de esto aún conservan gran importancia en las historias sagradas de ambas regiones hasta el día de hoy. Cada caso refleja procesos complejos de transculturación y la necesidad de una evaluación a fondo de cada espacio y su contextualización histórica (Pesoutova, 2019). Un estudio longitudinal en cada uno es completamente necesario para una mejor comprensión y preservación de este rico patrimonio. ${ }^{4}$

Estos ejemplos ilustran la presencia de los ancestros indígenas en la memoria cultural, y cómo las comunidades contemporáneas, en sus propios términos y desde sus propias experiencias, se reconectan con los paisajes circundantes y se posicionan dentro de su pasado. Estas celebraciones también contradicen la noción estereotipada de comunidades criollas desarraigadas sin una profunda relación espiritual con sus paisajes. El simbolismo de las prácticas en estos sitios contrasta con las descripciones históricas u otros planteamientos que sugieren continuidades y discontinuidades de prácticas ancestrales de diferentes orígenes. Si bien el reconocimiento de las agencias ancestrales indígenas en el contexto de la salud y el bienestar es la forma más consciente de recordarles, emerge además una forma inconsciente a través de prácticas corporales, el conocimiento codificado en los rituales, las tradiciones colectivas y el habitar (dwelling) en paisajes cargados de huellas históricas indígenas.

Las fuentes y cavernas dominicanas son espacios de memoria cuyos significados se componen de cosmologías pasadas, a veces fragmentadas, de diversos orígenes y situadas en paisajes compartidos. La memoria de los antepasados indígenas está codifi-

4. Uno de estos estudios se encuentra actualmente en fase de culminación a través del trabajo de Toño Arias Peláez titulada: La geografía religiosa-cultural de Mana y Viviana De La Rosa. cada en las tradiciones colectivas, a través de la morada en los paisajes dominicanos y el reconocimiento de los mismos como una importante fuente de sabiduría, inspiración y orientación moral.

\section{Las continuidades y el discurso colonial}

Dentro de las continuidades, la históricamente más comprobada es la continuidad del discurso colonial en la sociedad actual. Este discurso ha sido influyente en teorías como la transculturación, en estudios y actitudes hacia las religiones no oficiales y hacia la medicina popular caribeña. Términos como indio, brujo, idolatría, supersticiones, cuentos, atrasado o primitivo se asocian a menudo con las culturas y conocimientos medicinales de los antepasados, históricamente marginados. Ese discurso es muy influyente y perjudicial en las tradiciones curativas actuales expresando los conflictos religiosos desde el "discurso colonial" para demonizar la fe de "los otros". Muchos de los curanderos con los que he interactuado han sido acosados públicamente, sus altares quemados y se ha cuestionado su derecho para ejercer sus religiones. Algunos de esos casos de valores impugnados están literalmente impresos en los paisajes. Uno de estos ejemplos fue el charco de Tamaré, situado en La Jaiba, donde el significado del Charco se convirtió en un claro punto de conflicto por motivos religiosos.

\section{En el cruce de caminos de los paisajes curativos}

La historia de los paisajes curativos se ha desarrollado dentro de profundas transformaciones materiales y conceptuales de los paisajes. La colonización implicó la expropiación a gran escala de tierras y recursos naturales, la conquista espiritual y la profunda pérdida de culturas y conocimientos medicinales ancestrales. La colonización de La Española desencadenó también la introducción de nuevas religiones y la sinergia de las culturas medicinales, mientras que a su vez parte del conocimiento indígena comenzó a circular por el mundo. 
La cuestión de la contribución indígena al proceso de transculturación de las culturas medicinales sigue siendo especulativa, altamente compleja y sin conclusiones definitivas. A lo largo de estas reflexiones hemos querido dejar claro que la interpretación de cualquier patrimonio vivo del Caribe en términos de continuidad cultural indígena, incluso después de su contextualización histórica, sigue siendo compleja. Uno de los desafíos para desenmarañar su presencia en el intrincado proceso de transculturación dentro del contexto caribeño, es que las superposiciones epistemológicas y ontológicas pueden enmascarar similitudes o dificultar la comprensión de cómo su simbolismo se fusiona con sistemas de creencias introducidos desde otros lugares y por otros actores sociales. Al mismo tiempo, esta interacción también pudo dar lugar a cambios de significado, olvido cultural y sentimientos de desarraigo.

La fragmentación de la memoria por la conquista, colonización y asimilación forzada, junto con los profundos cambios demográficos y culturales, han creado obstáculos para reconstruir las historias de aquellos antepasados que han sido históricamente marginados. En búsqueda de raíces uno puede olvidarse de los rizomas caracterizados por el crecimiento nómada, la heterogeneidad y las cadenas semióticas, cuyos orígenes no son trazables.

Siguiendo la metáfora de Fernando Ortiz sobre el contrapunteo, estas reflexiones concluyen que la memoria cultural puede servir como uno de los dos lados del contrapunto al crear un contraste con el sesgo inherente a los archivos coloniales. Si bien es imposible determinar el origen exacto de ciertas tradiciones medicinales, es evidente que muchos aspectos de la historia de la medicina y de las prácticas curativas contemporáneas se complementan y contrastan entre sí y contribuyen a que comprendamos mejor el valor de los paisajes curativos.

Los paisajes curativos contemporáneos son testimonios del complejo proceso de transculturación a través del cual los antepasados caribeños recrearon su relación entre sí y con el medio ambiente circundante, de acuerdo con cosmovisiones y contextos socioculturales a menudo controvertidos. Las prácticas medicinales actuales muestran cómo los antepasados de los dominicanos improvisaban o aprendían en nuevos entornos desconocidos, transmitiendo conocimientos ecológicos que a menudo se articulan en un conjunto de prácticas culturales y enseñanzas a las siguientes generaciones.

La historia de la medicina dominicana habla de devastación, enfermedades, muertes y apropiación de recursos naturales y conocimientos. Sin embargo, al mismo tiempo, la información recuperada de los paisajes curativos actuales, también trasmite testimonios de supervivencias, resistencias y capacidad para sanarse, o encontrar unidad como comunidad en medio de atmósferas deshumanizadoras y alienantes marcadas por la violencia y la explotación.

\section{Referencias}

Acevedo-Rodríguez, P. \& Strong, M. (2012). The Catalogue of Seed Plants of West Indies. Washington, Estados Unidos: Smithonian Institution Scholarly Press.

Anderson-Cordova, K. (1990). Hispaniola and Puerto Rico: Indian Acculturation and Heterogeneity 1492-1550 (Ph.D. dissertation). Yale University. Ann Arbor: University Microfilms.

Anderson-Córdova, K. F. (2017). Surviving Spanish Conquest: Indian Fight, Flight, and Cultural Transformation in Hispaniola and Puerto Rico. Tuscaloosa, Estados Unidos: University of Alabama Press.

Alcocer, L. J. (1942) [1650]. Relación sumaria del estado presente de la Isla Espańola en las Indias Occidentales y cosas notables que hay en ella, de sus frutos y de algunos sucesos que han acontecido en ella, del Arzobispado de la ciudad de Santo Domingo de la dicha Isla y 
vidas de sus Arzobispos hasta el año de 1650. Boletín del Archivo General de la Nación, 5, 20-21.

Assmann, J. (2011). Cultural Memory and Early Civilization: Writing, Remembrance, and Political Imagination. Cambridge: Cambridge University Press.

Badura, B. (2013). Páginas de la historia del pueblo del Caney. Praga, República Checa: Karolinum.

Bender, B. (2002). Time and landscape. Current Anthropology, 43, 103-S112.

Blanco Díaz, A. (ed.). (2009). Escritos Históricos. Santo Domingo, República Dominicana: Búho.

Bolívar Aróstegui, N., González Díaz de Villegas, C. y Río Bolívar del, N. (1998). Ta Makuende Yaya y Las Reglas de Palo Monte. Mayonbe, Brillumba, Kimbisa y Shamalongo. La Habana, Cuba: Instituto Cubano del Libro Editorial José Martí.

Breton, R. (2015) [1665]. Dictionnaire caraïbe-francais. (D. Troiani transl). El caribe insular del siglo XVII. Tratado sobre la lengua y la cultura de los Callínago. Münich, Alemania: LINCOM.

Brendbekken, M. (1998). Hablando con la Mata. Santo Domingo, República Dominicana: Instituto de Medicina Dominicana.

Bollig, M. \& Bubenzer, O. (eds). (2009). African Landscapes: Interdisciplinary Approaches. New York, Estados Unidos: Springer.

Bouton, J., McKusick, M. B. \& Verin, P. (1640). Concerning The Savages Called Caribs. Account of the Establishment of the French in the Year 1635 on the Island of Martinique. A Paris: Chez S. Cramoisy. Recuperado de http://ehrafworldcultures.yale.edu/document?id=st13-003.

Cabrera, L. (1993) [1953]. El Monte. La Habana, Cuba: Letras Cubanas.

CITMA. (2007). Catálogo delas Cavernas Arqueológicas de la Provincia de Granma. [Inédito].
Deive, C. E. (2002). Antología de la flora y fauna de Santo Domingo en cronista y viajeros (Siglo XV$X X)$. Santo Domingo, República Dominicana: Amigos del Hogar.

Echagoian, J. (1942) [1568]. Relación de La Isla Española. In E. Rodríguez Demorizi (ed.), Relaciones Históricas de Santo Domingo. Ciudad Trujillo: Montalvo.

Exquemelin, A. O. (1971) [1678]. De Americaensche zee-rovers beschreven door A. O. Exquemelin die self alle dese roveryen, door noodt, bygewoont heeft. Laren, The Netherlands: A. J. Luitingh.

Fernández de Oviedo, G. (2002) [1535-1557]. Historia General y Natural De Las Indias. In C. E. Deive (ed.), Antología de la flora y fauna de Santo Domingo en cronista y viajeros (Siglo XV-XX). Santo Domingo, República Dominicana: Amigo del Hogar.

Germosén-Robineau, G. (2005). Farmacopea Vegetal Caribeña. Nicaragua: Editorial Universitaria, Unana.

Gesler, W. (1993). Therapeutic Landscapes - Theory and a case-study of Epidauros, Greece. Environ. Plan. D-Soc. Space, 11(2), 171-189.

Gil-Bermejo García, J. (1983). La Española Anotaciones Históricas (1600-1650). Sevilla, España: Escuela de Estudios Hispano-Americanos de Sevilla.

Gullick, C. J. M. R. (1985). Myths of Minority the changing traditions of Vincencian Caribs. Assen: Van Gorcum.

Hermans, R., Kolen, J. \& Renes, H. (2013). Landscape Biographies: Geographical, Historical and Archaeological Perspectives on the Production and Transmission of Landscapes: Geographical, Historical and Archaeological Perspectives on the Production and Transmission of Landscapes. Amsterdam, The Netherlands: Amsterdam University Press.

Herskovits, M. J. \& Herskovits, F. S. (1933). Outline of Dahomean Religious Belief. Memoirs of The American Anthropological Association. Menasha, Wis.: The American Anthropological Association. Recuperado de http://ehrafworldcultures.yale.edu/document?id=fa18-003. 
Ingold, T. (2002). Culture and the Perception of the Environment. In E. Croll \& D. Parkin (eds.) Bush Base, Forest Farm: Culture, Environment, and Development. London/New York: Routledge.

Las Casas, B., de (1992). Historia de las Indias. 3 vols. En A. Saint-Lu (ed.). Caracas, Venezuela: Fundación Biblioteca Ayacucho.

La Rosa Corzo, G. \& Robaína Jaramillo, R. (1995). Costumbres funerarias de los aborigenes de Cuba. La Habana, Cuba: Editorial Academia.

MacGaffey, W. (2001). Twins, Simbi Spirits, and Lwas in Kongo and Haiti. In L. M. Heywood (ed.), Central Africans and Cultural Transformations in the American Diaspora. Cambridge, Reino Unido: Cambridge University Press.

Méndez Nieto, J. (1989). Discursos medicinales. Salamanca, España: Universidad de Salamanca.

Mira Caballos, E. (1997). El indio antillano: repartimiento, encomienda y esclavitud: (1492-1542). Sevilla, España: Muñoz Moya y Montraveta.

Monardes, N. (1580). Primera, y segunda y tercera partes de la Historia medicinal de las cosas que se traen de nuestras Indias Occidentales, Sevilla, Espańa: Recuperado de //archive.org/details/ bub_gb_eAtm3cE1smAC.

Montey Tejada del, A. (1890). Historia de Santo Domingo. Santo Domingo, República Dominicana: Imp. García.

Moreau de Saint-Méry, L. E. (1796). Description topographique et politique de la partie espagnole de l'isle Saint-Domingue. Philadelphie, EE. UU.: L'auteur.

Ososki, A. L. (2004). Ethnobotany of rural and urban Dominican Republic: medicinal plants, women, and health. S.l.: s.n.

Ortiz, F. (1995) [1947]. Cuban counterpoint, tobacco and sugar. Durham etc.: Duke University Press.

Pané, R. (1498). Writings of Friar Roman on the Antiquities of the Indians, Which He Collected on Request of the Admiral with Diligence, as a Man Who Knows Their Language (ca. 1498).
Transl. Whitehead, N. L. (2011). OfCannibals and Kings. Primal Anthropology in Americas. Pennsylvania State University: University Press.

Pesoutova, J. (2019). Indigenous Ancestors and Healing Landscapes: Cultural Memory and Intercultural Communication in the Dominican Republic and Cuba. Leiden, Holanda: Sidestone. Accesso libre en: https://openaccess.leidenuniv.nl/ handle/1887/68891.

Perrin, M. (1987). Shamanistic Symptoms or Symbols? A Case of Indetermination (The Body of the Guajiro Shaman). Anthropos, $82,567-580$.

Portorreal, F. (2011). Plantas medicinales en el Este dominicano. Estudio etnobotánico en las provincias de Monte Plata, Hato Mayor y El Seibo de la República Dominicana. Santo Domingo, República Dominicana: Instituto de Investigaciones Científicas Universidad Central del Este.

Portuondo Zúńiga, O. (2012). El Departamento Oriental en Documentos, Tomo I (1510-1799). Santiago de Cuba, Cuba: Editorial Oriente.

Quiros-Moran, D. (2009). Guide to Afro-Cuban Herbalism. Bloomington, Estados Unidos: Author House.

Rodríguez Demorizi, E. (1944). Documentos para la Historia de la República Dominicana. Vol. I. Ciudad Trujillo: Montalvo.

Rodríguez Demorizi, E. (1945). Relaciones Históricas de Santo Domingo. Vol. II. Ciudad Trujillo: Montalvo.

Rodríguez Demorizi, E. (1947). Documentos para la Historia de la República Dominicana. Vol. II. Ciudad Trujillo: Montalvo.

Rodríguez Demorizi, E. (1957). Relaciones Históricas de Santo Domingo. Vol. III. Ciudad Trujillo: Montalvo.

Rodríguez Morel, G. (2007a). Cartas de Cabildo de Santo Domingo en el siglo XVII. Archivo General de la Nación Vol. XXXIV. Santo Domingo: Búho. 
Rodríguez Morel, G. (2007b). Cartas de la Real Audiencia de Santo Domingo (1530-1546). Santo Domingo: Archivo General de la Nación. Rodríguez Morel, G. (2011). Cartas de la Real Audiencia de Santo Domingo (1547-1575). Santo Domingo, República Dominicana: Archivo General de la Nación.

Rodríguez Morel, G. (2015). Cartas de la Real Audiencia de Santo Domingo (1575-1578). Santo Domingo, República Dominicana: Archivo General de la Nación.

Roig y Mesa, T. (1974). Plantas medicinales, aromáticas o venenosas de Cuba. La Habana, Cuba: Instituto del libro.

Russo, K. (2008). Healing landscapes: An historicalperspective. ProQuest Dissertations Publishing.

Santos-Granero, F. (1998). Writing History into the Landscape: Space, Myth, and Ritual in Contemporary Amazonia. American Ethnologist, 25(2), 128-148.

Sauer, C. O. (1925). The Morphology of Landscape. In J. Agnew, D. N. Livingstone \& A. Rogers (eds.), Human geography: an essential anthology. Great Britain: T. J. International Limited.

Sloane, H. (1707). A voyage to the islands Madera, Barbados, Nieves, S. Christophers and Jamaica with the natural history ... of the last of those islands; to which is prefix'd an introduction, wherein is an account of the inhabitants, air, waters, diseases, trade. London, Inglaterra: Printed by B. M. for the author.

Ulloa Hung, J. \& Valcárcel Rojas, R. (2016). Los Indigenas más allá de Colón. Indígenas e indios en el Caribe Presencia, legado y estudio (Vol. I).
Santo Domingo, República Dominicana: Instituto Tecnológico de Santo Domingo.

Valcárcel Rojas, R. (2012). Interacción colonial en un pueblo de indios encomendados: el Chorro de Maíta, Cuba. Ph.D. Disertación, Faculty Archaeology, Leiden University.

Valcárcel Rojas, R. \& Pérez Concepción, H. (2014). Indios de Holguín. Holguín, Cuba: La Mezquita.

Valcárcel Rojas, R. (2016). Cuba. Indios después de Colón.), Los Indigenas más allá de Colón. Indigenas e indios en el Caribe Presencia, legado y estudio. En J. Ulloa Hung, \& R. Valcárel Rojas (eds.). Santo Domingo, República Dominicana: Instituto Tecnológico de Santo Domingo.

Vega Suñol, J. (2014). Los aborígenes de Cuba en la etnohistoria de Holguín: un acercamiento a los libros bautismales de los siglos Xviı y xix. In Valcárcel Rojas, R. \& H. Pérez Concepción, Indios de Holguin. Holguín, Cuba: La Mezquita.

Taylor, D. (1952). Tales and Legends of the Dominican Caribs. The Journal of American Folklore, 65, 267-279.

Viveiros De Castro, E. (1998). Cosmological Deixsis and Amerindian Perspectivism. Cambridge, Reino Unido: King's College Cambridge.

Yaremko, J. (2016). Indigenous passages to Cuba, 15151900. Gainesville, Estados Unidos: University Press of Florida.

\section{Datos de filiación}

Jana Pesoutova. Después de completar su tesis de maestría en psicología social, realizó su investigación doctoral en la Facultad de Arqueología de la Universidad de Leiden. La tesis de Jana se llevó a cabo como parte del Proyecto NEXUS 1492. Encuentro del Nuevo Mundo con un Mundo en Globalización dirigido por la Dra. Corinne Hofman y auspiciado por el Consejo Europeo de Investigación (ERC). Su intereses de investigación esencialmente se concentran en historia de las prácticas curativas, medicina popular, paisajes sagrados, memoria cultural. 